generated from a linear model could be a function of both the baseline CD4 level and viral loads. Further studies with larger sample sizes are needed to resolve these discrepancies.

Shenghan Lai, J. Bryan Page, Hong Lai

Departments of Medicine,

Psychiatry and Epidemiology, University of Miami School of Medicine, Miami, Florida 33136, USA

\section{HIV an illusion}

SIR - In an editorial ${ }^{1}$ in the 19 January issue of Nature, John Maddox invited "Duesberg and his associates" to comment on the "HIV-1 dynamics" papers published the previous week, indicating that these new results should prove an embarrassment to us. Although we do not think that a scientist should be embarrassed for pointing out inconsistencies and paradoxes in a hypothesis that have only been reportedly resolved 10 years later, we nonetheless prepared a fully referenced, approximately 2,000-word critique of the Ho et $a l^{2}$ and Wei et $a l^{3}$ papers that we believed met the criteria of "not being longer than it needs to be, and pertaining to the papers at hand" that Maddox set out in his widely read challenge.

Unfortunately, he did not share our view and agreed to publish only a radically shortened version, and only after he had personally "gone over it with a fine-tooth comb" to remove our perceived misrepresentations of the issues. We found these new conditions so totally at variance with the spirit of free and fair scientific debate that we could not agree to them.

Readers of Nature who are interested in these questions, and feel that they do not need to be protected by Maddox from our ill-conceived logic, can find the complete text of our commentary in the monograph supplement to the most recent issue of Genetica ${ }^{4}$. Here we would point out only that the central claim of the Ho et al. ${ }^{2}$ and Wei et al. ${ }^{3}$ papers - that $10^{5} \mathrm{HIV}$ virions per ml plasma can be detected in AIDS patients with various nucleic-acid amplification assays - is misleading. The senior author of the Wei et al. paper has previously claimed that the PCR method they used overestimates by at least 60,000 times the real titre of infectious $\mathrm{HIV}^{5}$ : $100,000 / 60,000$ is 1.7 infectious HIVs per $\mathrm{ml}$, hardly the "virological mayhem" alluded to by Wain-Hobson ${ }^{6}$. Further, Ho and a different group of collaborators have just shown" that more than 10,000 "plasma virions", detected by the branched-DNA amplification assay used in their Nature paper, correspond to less than one (!) infectious virus per $\mathrm{ml}$. And infectious units, after all, are the only clinically relevant criteria for a viral pathogen.

Finally, in view of Wain-Hobson's statement ${ }^{6}$ that "the concordance of their [Wei and Ho's] data is remarkable", note that Loveday et al. ${ }^{8}$ report the use of a PCRbased assay and find only $200 \mathrm{HIV}$ "virion RNAs" per ml of serum of AIDS patients $-1,000$ times less than Ho and Wei. So much for the "remarkable concordance".

\section{Peter Duesberg}

Department of Molecular and Cellular

Biology, University of California,

Berkeley, California 94720, USA

\section{Harvey Bialy}

Bio/Technology, New York,

New York 10010, USA

1. Maddox, J. Nature 373, 189 (1995).

2. Ho, D.D. et al. Nature $373,123-126$ (1995).

3. Wei, X. et al. Nature 373, 117-122 (1995).

4. Duesberg, P. \& Bialy, H. Genetica Suppl. (in the press)

5. Piatak, M. et al. Science 259, 1749-1754 (1993).

6. Wain-Hobson, S. Nature 373, 102 (1995).

7. Cao, Y. et al. New Engl. J. Med. 332, 201-208 (1995).

8. Loveday, C. et al. Lancet 345, 820-824 (1995).

Peter Duesberg was offered space in Scientific Correspondence for 500 words of his own choice, but declined. - Editor, Scientific Correspondence.

SIR - The most recent AIDS press releases published as two "scientific articles" in your magazine ${ }^{1,2}$ indeed are the most clever and, if possible, the most deadly yet! Since March 1987, when Duesberg first published his critique of retrovirology" and his proof that the "AIDS virus" is not sufficient to cause AIDS, the AIDS/HIV entrepreneurial gaggle have railed against him both professionally and financially. Rather than test Duesberg's hypothesis or for that matter fund him to test his own hypothesis, you change your model, which has not saved a single life, to suit your own purposes, from HIV kills CD4 cells directly, to HIV kills cells indirectly, and now back to the latest direct kill model of Wei et al. ${ }^{1}$ and Ho et al. ${ }^{2}$.

Wei et al. ${ }^{1}$ and Ho et al. ${ }^{2}$ describe a viraemia that on administration of certain drugs drops exponentially and raises CD4 counts exponentially, seemingly without a trace of "mayhem". What is this viraemia of billions of RNA particles that can only be seen with an undocumented branch-PCR or PCR but not with a functional infectivity test? How do the authors know that these RNA particles are infectious and not defective? Is it reverse transcriptase activity? Is it some protein that is unique to the quasispecies HIV? The tests for HIV are all flawed. What is this free virus? How does one have free virus after immune response? Are not symptomatic people with AIDS HIV-positive, that is, don't they have antibodies against HIV? So what is free virus?

The Wei et al. and Ho et al. models do not account for other probable immune activity and the uniqueness of each individual. Haynes and Fauci showed in 1978 that hydrocortisone selectively caused CD4 cells to hide in tissue. Indeed, what effect do multiple drugs have on $\mathrm{CD} 4$ cells? The notion of clearance of one billion CD4 cells per day versus one billion virions per day is not defined or addressed, nor can it be! No one else has access to either the unapproved drugs or the branch PCR technology! What is the benchmark rate for the turnover of CD4 cells in the general population?

To counter the 42 case studies of Wei et $a l{ }^{1}$ and Ho et al. ${ }^{2}$, we at HEAL (Health Education AIDS Liason) can provide at least 42 people who are western-blot-positive for 'HIV', have low T4 cells, who are not using orthodox procedures, and have been healthy for years! On the other hand, we can also provide you with hundreds of ' $\mathrm{HIV}^{+}$' people with high T4 cells, who were then hospitalized with opportunistic diseases! Not to mention the thousands of AIDS cases without HIV which were conveniently renamed idiopathic CD lymphocytopenia.

We at HEAL maintain that what is called AIDS is no more complicated than a recreational drug-fear-medical drug disease syndrome which, with the exception of acute medical care, is out of the purview of orthodox medicine.

\section{F. R. Buianouckas}

Department of Mathematics

and Computer Science,

Bronx Community College,

City University, Bronx,

New York 104353, USA

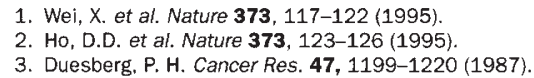

\section{Toxic shock}

SIR - The recovery rate of $\mathrm{CD}^{+}{ }^{+} \mathrm{T}$ cells reported by Wei et al. ${ }^{1}$ and Ho et al. ${ }^{2}$ in HIV patients following therapy is remarkably similar to that observed in another acute clinical condition. We have documented lymphocyte counts and proportions of CD4 cells double-staining for CD45 isoforms in three patients during episodes of toxic shock syndrome and one following toxic shock-like syndrome.

In these clinically defined conditions, bacterial superantigen initially induces massive T-cell and monocyte activation. There is subsequent apoptosis of the activated $\mathrm{CD}^{+}$cells, during which patients demonstrate a lymphopenia ${ }^{3}$, followed by the return to normality of the lymphocyte count as patients recuperate. The mean rate of change in the counts in the first 2 weeks of recovery was 2.1 , which compares with 2.0 (ref. 1) and 1.8 (ref. 2).

The similarity in rates of recovery suggest that this rate has some value as a common measure of maximal CD4 T-cell output to the circulation in adults. Slower rates may be observed, for instance, in patients following radiotherapy or chemotherapy ${ }^{4}$. This rate decreases with time; it took one patient 14 months to reach a final $\mathrm{CD} 4^{+}$lymphocyte count of $1.4 \times 10^{9}$ cells $\mathrm{cm}^{-3}$. The nature or mechanisms of the brake on this rapid prolifer- 